\title{
Quantitative phenotyping of grey leaf spot disease in maize using real-time PCR
}

\author{
J. Korsman • B. Meisel • F. J. Kloppers • \\ B. G. Crampton $\cdot$ D. K. Berger
}

Accepted: 1 December 2011 / Published online: 20 December 2011

C The Author(s) 2011. This article is published with open access at Springerlink.com

\begin{abstract}
Grey leaf spot is an important maize foliar disease caused by the fungal pathogens Cercospora zeae-maydis and Cercospora zeina. Although methods exist to detect these Cercospora species in maize, current techniques do not allow quantification of the fungi in planta. We developed a real-time SYBR ${ }^{\circledR}$ Green PCR assay for quantification of grey leaf spot disease in maize based on the amplification of a fragment of a cytochrome P450 reductase (cprl) gene. In planta fungal DNA content was normalised to a maize glutathione S-transferase III gene (gst3) to yield values
\end{abstract}

Electronic supplementary material The online version of this article (doi:10.1007/s10658-011-9920-1) contains supplementary material, which is available to authorized users.

J. Korsman • B. Meisel • B. G. Crampton •

D. K. Berger $(\bowtie)$

Department of Plant Science,

Forestry and Agricultural Biotechnology Institute (FABI),

University of Pretoria,

Private Bag X20,

Hatfield 0028, South Africa

e-mail: dave.berger@fabi.up.ac.za

\section{F. J. Kloppers}

PANNAR SEED (Pty) Ltd,

PO Box 19, Greytown, South Africa

Present Address:

B. Meisel

Monsanto, South Africa (Pty) Ltd,

PO Box 69933, Bryanston 2021, South Africa of ng Cercospora DNA/mg maize DNA. The assay was specific to the two Cercospora spp., and we observed no amplification of the cprl fragment in non-target maize leaf pathogens or saprophytes. The assay was employed to quantify C. zeina in glasshouse inoculated maize plants and grey leaf spot infected field plants of resistant and susceptible maize lines. In both instances, C. zeina DNA content correlated with symptomatic leaf lesion area, and the susceptible maize line contained significantly more $C$. zeina DNA than the resistant line. Sequence differences between the C. zeina and C. zeae-maydis cprl amplicons enabled us to perform melt curve analyses to identify the Cercospora species causing grey leaf spot at a particular location. This assay has application in the early detection and quantification of Cercospora spp., both of which are important tools in grey leaf spot disease management and maize breeding programmes.

Keywords Cercospora zeae-maydis · Cercospora zeina · Precision phenotyping · Quantitative PCR · Grey leaf spot $\cdot$ Gray leaf spot $\cdot$ Real-time PCR · qPCR
Abbreviations
$\mathrm{Ct} \quad$ cycle threshold
cprl cytochrome $\mathrm{P} 450$ reductase 1 gene
dpi days post inoculation
GLS grey leaf spot/gray leaf spot
gst3 glutathione S-transferase III gene
ITS internal transcribed spacer
rDNA ribosomal DNA 


\section{Introduction}

Grey/gray leaf spot (GLS) caused by fungi of the genus Cercospora is a foliar disease of maize of great economic importance in many countries. GLS can reduce grain yield by 20 to $60 \%$ depending on the level of susceptibility of the hybrid (Latterell and Rossi 1983, Ward et al. 1994). Infected maize crop debris is the source of primary inoculum. After periods of high humidity spores are wind-dispersed or rainsplashed onto bottom leaves of the plant and the disease then progresses upwards. Some infection later in the season also takes place when spores are blown in from adjacent fields. Typically, lesions develop from small spots which then become tan and rectangular. GLS has a long latent period with 14 to 28 days after infection before lesions produce conidia under humid conditions, which can be seen as a greyish cast. Lesions first run parallel with leaf veins but lesion expansion can result in blighting of entire leaves due to coalescing of lesions (Ward et al. 1999).

Depending on the geographic region, GLS disease of maize can be either caused by Cercospora zeaemaydis (formerly known as C. zeae-maydis Group I), which has been found throughout various areas of the U.S.A., Canada, Mexico and Brazil, or Cercospora zeina (formerly known as C. zeae-maydis Group II), which has been reported in the Eastern maize growing states of the U.S.A., Brazil and sub-Saharan Africa (Wang et al. 1998, Dunkle and Levy 2000, Goodwin et al. 2001, Zhu et al. 2002, Okori et al. 2003, Shim and Dunkle 2005, Crous et al. 2006, Brunelli et al. 2008, Meisel et al. 2009). Characteristics and dimensions of conidia and conidiophores produced on infected plants or nutrient media were found to be unreliable criteria for taxonomic differentiation of $C$. zeae-maydis and C. zeina (Wang et al. 1998). Crous et al. (2006) developed a PCR-based test to distinguish the two species based on species-specific primers designed from the histone $\mathrm{H} 3$ gene. Dunkle and Levy (2000) employed restriction analysis of internal transcribed spacer (ITS) and 5.8S ribosomal DNA (rDNA) regions to differentiate $C$. zeae-maydis and $C$. zeina isolates. Although these methods can distinguish the causal agents of GLS in maize, there are currently no available techniques to quantify Cercospora spp. levels in infected maize leaves.

Quantitative PCR (qPCR) offers a reliable and sensitive method for detecting and quantifying fungi in planta, and has particular application in pathogen detection prior to symptom development. Recently, De Coninck and co-workers (2011) developed a qPCR assay to quantify Cercospora beticola in sugar beet leaves, which will help breeders to discriminate minor differences in resistance in a segregating population. A number of recent studies have employed qPCR to quantify pathogens on maize material. Fusarium spp. are a major source of mycotoxin contamination in maize, and quantification of fungal biomass is essential to understanding interactions between individual species in disease development. Waalwijk et al. (2008) developed a qPCR assay based on a mycotoxin biosynthesis gene to detect mycotoxin producing Fusarium verticillioides isolates in maize grain from subsistence farmers in South Africa, and correlated fungal DNA content with mycotoxin levels. Nicolaisen et al. (2009) established a SYBR Green qPCR assay based on the elongation factor 1 alpha gene to detect and quantify eleven Fusarium sp. in maize and wheat field material. These studies demonstrate the importance of qPCR for quantification of fungal pathogens in order to select resistant plants in breeding programmes.

The objective of this study was to develop a quantitative PCR assay (qPCR) to measure the amount of Cercospora sp. DNA in infected maize leaves. We hypothesised that a qPCR assay based on cpr1, a putative cytochrome P450 reductase (van den Brink et al. 1995), would accurately quantify Cercospora spp. DNA content in glasshouse inoculated and field infected maize leaves. Results obtained were significant as the qPCR assay was specific to Cercospora spp., and showed good correlation between C. zeina DNA content and leaf lesion area measured by digital imaging. In addition, we could distinguish between $C$. zeae-maydis and C. zeina, both causal agents of GLS in maize. Quantification of Cercospora spp. in maize leaves has important application in the breeding and selection of GLS resistant maize lines.

\section{Materials and Methods}

Biological material and host plant infection

The C. zeae-maydis ex-type culture CBS 117757 as well as other C. zeae-maydis cultures CBS 117755 , CBS 117758, CBS 117759, CBS 117760, CBS 
117761, CBS 117762, CBS 117763, the C. zeina extype culture CBS118820, and Cercospora sp. CPC 12062 were obtained from the culture collection of the Centraalbureau voor Schimmelcultures, Utrecht, The Netherlands. The C. zeina cultures CMW 25463, CMW 25467, CMW 25445, CMW 25442, CMW 25459, CMW 25465, CMW 25462, CMW 25454, CMW 25452 and CMW 25466 are described in Meisel et al. 2009. Fungal cultures were grown on $\mathrm{V} 8$ medium ( $800 \mathrm{ml}$ of distilled water, $200 \mathrm{ml}$ of V8 juice, $15 \mathrm{~g}$ of agar, and $2 \mathrm{~g}$ of $\mathrm{CaCO}_{3}$ ) in the dark at $25^{\circ} \mathrm{C}$. DNA from $C$. zeae-maydis cultures WB IL and WB KS, and from C. zeina cultures WB VA, WB UG and WB BZ were obtained from W-B Shim, Texas A \& M University, College Station, Texas, USA.

Maize leaves showing typical symptoms of GLS (C. zeina), northern corn leaf blight (Exserohilum turcicum), Phaeosphaeria leaf spot (Phaeosphaeria maydis), Hyalothyridium leaf spot (Hyalothyridium maydis), zonate leaf spot (Gloeocercospora sorghi) and tropical Diplodia (Stenocarpella macrospora) were collected from Greytown and other sites in South Africa. Maize leaves showing symptoms of GLS were collected from fields in Brookston, Indiana, USA; Argentina, Mpongwe and Gart farm, Zambia. DNA was isolated under quarantine conditions from diseased maize material collected outside South Africa.

Saprophytes were isolated from GLS lesions by scraping a needle over a lesion and streaking it out on V8 medium. Single spores of Epicoccum sp., Cladosporium sp., Phoma sp., Tilletiopsis sp., Sporobolomyces sp. and Cryptococcus sp. were placed on separate plates and grown for DNA isolation. Sequences of the ITS region amplified using primers ITS1/4 (White et al., 1990) were used for identification by BLASTN analysis against GenBank (Altschul et al. 1990).

Maize plants of a C. zeina-susceptible hybrid PAN $6724 \mathrm{~B}$ were planted in a glasshouse at $28+/-4^{\circ} \mathrm{C}$ under a $16 \mathrm{~h}$ day length. Sporulation of $C$. zeina culture CMW 25463 grown on V8 medium was achieved by incubating the plates under equal periods of light and dark (12 h of fluorescent light, $12 \mathrm{~h}$ of dark). Conidia were dislodged with a brush and rinsed with $0.01 \%$ Tween 20 . The inoculum was diluted to $3 \times 10^{5}$ conidia/ml and applied onto both surfaces of all three leaves (V3-stage) of the maize plants with a small brush. Control plants were treated with $0.01 \%$ Tween 20. Plants were covered with transparent plastic bags for 5 days to increase humidity levels. Leaves developed typical lesions 13 to 19 dpi. Leaf pieces from different plants were photographed using a SLR digital camera for image analysis, and sampled at 19 days post inoculation (dpi) for DNA extraction.

Field grown maize material was collected from two inbred lines, one that is moderately resistant to grey leaf spot disease (line PEX1), and another that is susceptible (line PEX2). Leaf samples were taken 15 weeks after planting from nine individual plants from each line that were positioned randomly within a field site situated in Kwazulu-Natal Province, South Africa. Grey leaf spot disease is prevalent in this region, and therefore the plants were exposed to a natural inoculum of C. zeina (Meisel et al., 2009). A $12 \mathrm{~cm}$ length of the leaf immediately above the lowest cob from each plant was marked with a permanent black marker pen. Photographs were taken prior to sampling of the leaf piece for subsequent DNA extraction.

Digital image analysis

The proportional areas of maize leaf pieces with grey leaf spot lesions from the glasshouse and field experiments were calculated from the photographs of the $12 \mathrm{~cm}$ leaf pieces using ASSESS 2.7 software (L. Lamari, American Phytopathological Society, St. Paul, MN, USA), as described in De Coninck et al., 2011.

\section{DNA extraction from fungi and plants}

DNA from 50 to $100 \mathrm{mg}$ of fungal cultures, as well as from 50 to $100 \mathrm{mg}$ of control or diseased maize leaves was isolated according to Moller et al. (1992). Integrity of the DNA was checked on a $0.8 \%$ agarose gel and concentration was determined with a NanoDrop $^{\mathrm{TM}} 1000$ spectrophotometer (Thermo Scientific) at $260 \mathrm{~nm}$.

Conventional and quantitative PCR amplification

Two cDNA sequences of a $C$. zeae-maydis putative cytochrome $\mathrm{P} 450$ reductase (GenBank accession numbers AF448828 and FG242129) were used to compile a composite sequence for primer design, resulting in primers CPR1_1F (5'-TCCACTCTCGCTCAATTCG-3') and CPR1_1R (5'-GCCTTCATCGCCATATGTTC-3'). These primers, designated CPR1_1, were used to amplify a $1.1 \mathrm{~kb}$ product from C. zeina genomic DNA, that 
was sequenced on an ABI PRISM ${ }^{\mathrm{TM}} 3100$ Automated DNA sequencer (Applied Biosystems) using the ABI Prism Big Dye Terminator Cycle sequencing reaction kit v3.1 (Applied Biosystems). The internal primers, designated CPR1_2, and named and CPR1_2F (5'TGAACTACGCGCTCAATG-3') and CPR1_2R (5'TCTCTCTTGGACGAAACC-3') were designed in two short regions of $100 \%$ identity between the two species. The primers GST3F (5'-GGAGCCCTGAGTC GAATAAAAG-3') and GST3R (5'-AACACACAC GAAAGGCAACAGT-3') were used to amplify a 106 bp-fragment of the glutathione S-transferase III gene gst3 from maize (GenBank accession number X06755).

For conventional PCR, reaction volumes of $15 \mu \mathrm{l}$ consisted of $1 \mathrm{x} \mathrm{NH}_{4}$ PCR reaction buffer, $2.7 \mathrm{mM}$ of $\mathrm{MgCl}_{2}, 0.1 \mu \mathrm{M}$ of each dNTP (Bioline), $0.2 \mu \mathrm{M}$ each of the primers, $1 \mathrm{U}$ of BIOTAQ ${ }^{\mathrm{TM}}$ DNA Polymerase (Bioline), $11.15 \mu \mathrm{l}$ of sterile distilled water and $10 \mathrm{ng}$ of DNA template. Cycling conditions were $2 \mathrm{~min}$ at $94^{\circ} \mathrm{C}$ followed by $35 \mathrm{x}\left(15 \mathrm{~s}\right.$ at $94^{\circ} \mathrm{C}, 15 \mathrm{~s}$ at $60^{\circ} \mathrm{C}, 20 \mathrm{~s}$ at $\left.72^{\circ} \mathrm{C}\right)$. A final elongation step was performed at $72^{\circ} \mathrm{C}$ for $5 \mathrm{~min}$. Quality of all PCR products was verified by gel electrophoresis.

The cprl-and gst3-fragments amplified in conventional PCR were ligated into the pJET1.2/blunt vector from the CloneJETTM PCR Cloning Kit (Fermentas) and subsequently transformed into chemically competent Escherichia coli using the manufacturer's instructions. Transformed E. coli were grown at $37^{\circ} \mathrm{C}$ overnight in Luria Bertani broth supplemented with $100 \mu \mathrm{g} / \mathrm{ml} \mathrm{am-}$ picillin. Purification of the plasmid DNA was performed using the Invisorb Spin Plasmid Mini Two Kit (Invitek). Plasmid DNA was used as template for sequencing reactions as described above. Sequences were checked by BLASTN (Altschul et al. 1990).

Quantitative PCR amplifications were performed in a total volume of $10 \mu \mathrm{l}$ on a LightCycler ${ }^{\circledR} 480$ instrument (Roche Diagnostics Corp.). Each reaction contained $1 \mu \mathrm{l}$ of the DNA template or water in the non-template controls, $5 \mu$ l of the LightCycler ${ }^{\circledR} 480$ SYBR Green I Master Mix (Roche Diagnostics Corp.), $0.2 \mu \mathrm{M}$ of each primer, and $3.6 \mu \mathrm{l}$ of sterile distilled water. Each PCR was run in triplicate. Cycling conditions consisted of $5 \mathrm{~min}$ at $95^{\circ} \mathrm{C}$ followed by $45 \mathrm{x}\left(10 \mathrm{~s}\right.$ at $95^{\circ} \mathrm{C}, 10 \mathrm{~s}$ at $60^{\circ} \mathrm{C}, 5 \mathrm{~s}$ at $\left.72^{\circ} \mathrm{C}\right)$. Fluorescence was detected at the end of each elongation step. The amplification specificity of the PCR was investigated by melting curve analysis after every run.
The specificity of the CPR1_2 primers was tested on $10 \mathrm{ng}$ of DNA isolated from healthy maize leaves and maize leaves with typical symptoms of GLS (C. zeaemaydis and C. zeina), northern corn leaf blight (E. turcicum), Phaeosphaeria leaf spot (P. maydis), Hyalothyridium leaf spot (H. maydis), zonate leaf spot (G. sorghi), tropical Diplodia (S. macrospora), and a number of fungi and yeast isolated from GLS lesions (Epicoccum sp., Cladosporium sp., Phoma sp., Tilletiopsis sp., Sporobolomyces sp., Cryptococcus sp.). The specificity of the GST3 primers was tested on $10 \mathrm{ng}$ of DNA isolated from healthy maize leaves, C. zeina, and C. zeae-maydis cultures and lesion samples. To exclude false negative results template DNA samples from lesions were tested for PCR amplification using primers ITS1/4 following the method of White et al. (1990).

In order to estimate the amount of fungal DNA in the infected leaf samples, DNA extracted from pure C. zeina and $C$. zeae-maydis cultures was diluted in maize DNA of concentration $10 \mathrm{ng}^{-1} \mathrm{l}^{-1}$. The final fungal DNA concentrations were $5,1,5 \times 10^{-1}, 2.5 \times 10^{-1}, 1 \times 10^{-1}, 5 \times 10^{-2}$,

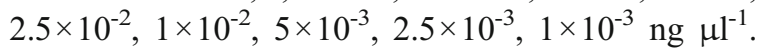
These dilutions were used to determine the detection limits of the CPR1_2 primer pair in a simulated lesion sample. A serial dilution of DNA extracted from healthy leaves $\left(2 \times 10^{1}, 1.5 \times 10^{1}, 1.25 \times 10^{1}, 1 \times 10^{1}, 5,1,5 \times 10^{-1}\right.$, $1 \times 10^{-1}, 5 \times 10^{-2} \mathrm{ng}^{-1} \mathrm{l}^{-1}$ ) was prepared to measure detection limits of the GST3 primers.

Standard curves were prepared by plotting $\log _{10}$ of the DNA concentration of known standards against the cycle number at which the fluorescent signal from the amplified PCR products surpassed the detection threshold. Regression curves were drawn and the qPCR efficiency was calculated as equal to $10^{(-1 / \text { slope })}$, the optimal efficiency thus equalling two. The amount of target DNA for unknown samples was extrapolated from the respective standard curves. To normalise gene quantification between different samples the amount of fungal cprl was divided by the amount of plant gst 3 quantified in infected leaves.

\section{Results}

Design of a specific PCR assay for Cercospora spp. in infected maize leaves

CPR1_1 primers were designed to the sequence of the C. zeae-maydis cprl gene, which encodes a 
Fig. 1 Alignment of a

$164 \mathrm{bp}$ fragment of $c p r 1$ from C. zeae-maydis CBS 117757 (Czm_cpr1) and $C$. zeina CBS 118820

(Cz_cpr1). The CPR1_2F and CPR1_2R primers used for the qPCR assay that are identical between the species are shown. NlaVI sites are underlined. Consensus nucleotides are indicated with an asterisk
5' TGAACTACGCGCTCAATG 3' CPR1_2F primer

1

Czm_cpr1

$\mathrm{Cz}$ cpr1

TGAACTACGCGCTCAATGGTCCACGAAACAAGTACGATGGCATCCACGTCCCGGTCCACA TGAACTACGCGCTCAATGGTCCACGAAACAAATACGATGGCATCCACTTCCCGGTTCACA $* * * * * * * * * * * * * * * * * * * * * * * * * * * * * * * * * * * * * * * * * * * * * * * * * * * * * * * * *$

61

120

Czm_cpr1

Cz_cpr1

TTCGACACTCGAACTTCAAGCTCCCCTCGGATCCAAGCAAGCCGATCATCATGGTTGGCC TTCGACACTCGAACTTCAAGCTCCCCTCAGACCCAAGCAAGCCCATTATCATGGTTGGTC

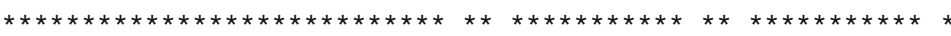

$121 \quad 164$

CTGGTACCGGCGTTGCTCCATTCCGCGGTTTCGTCCAAGAGAGA CTGGCACCGGCGTTGCTCCATTCCGCGGTTTCGTCCAAGAGAGA $\star * * * * * * * * * * * * * * * * * * * * * * * * * * * * * * * * * * * * * * * * * *$

CPR1_2R primer 3'CCAAAGCAGGTTCTCTCT 5' cytochrome P450 reductase first described in A. niger (van den Brink et al. 1995). These primers were used to amplify $967 \mathrm{bp}$ of this gene from C. zeae-maydis and 1,024 bp from C. zeina. Alignment of the cprl gene sequences from C. zeae-maydis and C. zeina enabled us to design internal primers (designated CPR1_2; see Materials and Methods) to conserved areas of the gene sequence (Fig. 1). Conventional and quantitative PCR produced a $164 \mathrm{bp}$ fragment in C. zeina and C. zeae-maydis isolates, but no amplicon was obtained from uninfected maize leaves or leaves infected with non-target maize pathogens
(Exserohilum turcicum, Phaeosphaeria maydis, Hyalothyridum maydis, Gloeocercospora sorghi, Stenocarpella macrosporum) (Fig. 2a). In addition, the CPR1_2 primer set did not produce an amplification product from saprophytic organisms (Epicoccum sp, Cladosporium sp., Phoma sp., Tilletiopsis sp., Sporobolomyces coprosmae, Cryptococcus flavescens) isolated from maize leaves. As a check for DNA quality, all samples from infected leaves and saprophytic organisms were successfully subjected to conventional PCR analysis using the ITS1 and ITS4 primers (Fig. 2c).

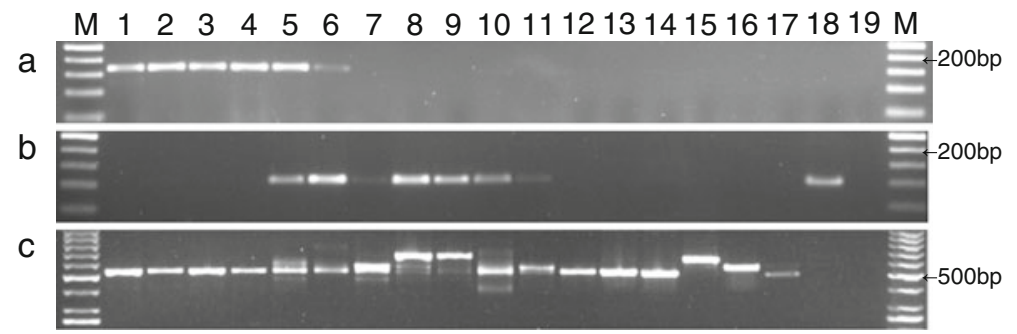

Fig. 2 PCR amplification of cprl a, gst 3 b and ITS1/4 c gene fragments from C. zeae-maydis and C. zeina cultures, DNA extracted from grey leaf spot lesions, other maize foliar pathogens, and saprophytic organisms isolated from grey leaf spot lesions. a CPR1_2 primers amplified fragments of $164 \mathrm{bp}$ from C. zeaemaydis and C. zeina, but not from other fungal pathogens and saprophytes isolated from grey leaf spot lesions. b GST primers amplified the gst 3 fragment only from samples derived from lesions on maize leaves. c The ITS1/4 region was amplified from all samples containing fungi/yeast and indicates DNA quality is adequate for DNA amplification. Lanes M, $50 \mathrm{bp}$ molecular marker (Fermentas). Templates used for each reaction were as follows: lanes 1-4, C. zeae-maydis CBS117755, C. zeae-maydis CBS117757, C. zeina CBS118820, C. zeina CMW25467 respectively; lanes 5-6, DNA isolated from lesions containing C. zeae-maydis from Argentina, and C. zeina from Greytown, RSA, respectively; lanes 7-11, DNA isolated from maize foliar diseases caused by Exserohilum turcicum (Northern corn leaf blight), Phaeosphaeria maydis (Phaeosphaeria leaf spot), Hyalothyridum maydis (Hyalothyridum leaf spot), Gloeocercospora sorghi (zonate leaf spot), Stenocarpella macrosporum (tropical diplodia), respectively; lanes 12-17, grey leaf spot saprophytes Epicoccum sp., Cladosporium sp, Phoma sp., Tilletiopsis sp., Sporobolomyces coprosmae and Cryptococcus flavescens, respectively; lane 18, non-diseased maize tissue; lane 19, no template PCR control 
Since cpr1 appears to be conserved in many fungal species, the specificity of the primers was verified by comparison to corresponding regions of the cpr 1 orthologues from other fungi available from GenBank (Supplementary Figure 1). The closest cprl orthologue is from the non-plant pathogen Podospora anserina, and this shows five and four mismatches with the CPR1_2F and CPR12R primers, respectively (Supplementary Figure 1). Other close orthologues from plant pathogens such as Pyrenophora spp. pathogenic on wheat, as well as Alternaria brassicicola, show increasing numbers of mismatches with the primers. It is therefore unlikely that amplification would occur from related pathogens on maize under the stringent conditions of the qPCR assay. This was borne out by the empirical evidence that shows no amplification from other fungi from maize (Fig. 2a), whose cprl sequences are not yet available on GenBank.

Conventional PCR with GST3F/GST3R primers produced specific amplicons of the expected $106 \mathrm{bp}$ when templates contained DNA from maize (Fig. 2b). Sequencing of gst 3 amplicons showed a nucleotide sequence exhibiting $100 \%$ identity with the gst 3 gene from Zea mays (GenBank accession number X06755). No PCR products were amplified from pure fungal cultures of C. zeae-maydis or C. zeina using the GST3F/GST3R primers (Fig. 2b).

qPCR method to quantify Cercopsora spp. in infected maize tissue

To quantify the pathogen in biological samples, a dilution series of genomic DNA from C. zeina and C. zeae-maydis was added to $10 \mathrm{ng}$ of DNA extracted from healthy maize creating progressively lower fungal DNA concentrations from 5 to $1 \times 10^{-3} \mathrm{ng} \mathrm{\mu l}^{-1}$ to generate standard curves for cprl (Fig. 3a and b, respectively). Efficiency of amplification of the 164 bp cprl fragment in maize carrier DNA was 1.84 , with a minimum detection limit of $5 \mathrm{pgC}$. zeina or C. zeae-maydis DNA. Quantifications of the pathogens showed a linear relationship between $\log _{10}$ values of the amount of DNA and cycle threshold values, indicating that the method is suitable as a quantitative assay over the concentration range tested. The qPCR efficiency of maize gst 3 was 1.68 (Fig. 3c). Both melt curve analyses and agarose gel electrophoresis of qPCR reactions indicated that a single product was
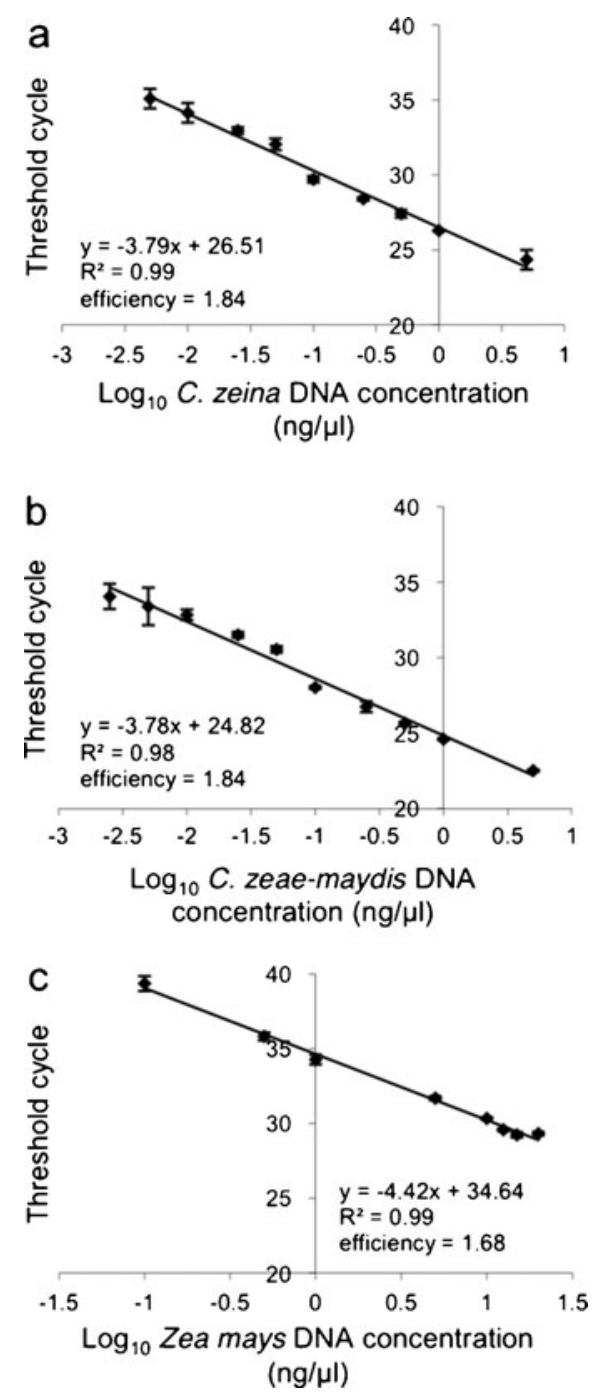

Fig. 3 Standard curves used for qPCR assay to quantify $C$. zeina and C. zeae-maydis in planta. The graphs illustrate the efficiency and sensitivity of cprl and gst 3 fragment amplification using the CPR1_2 primers and GST primers, respectively. Figures a and b represent standard curves of $C$. zeina and $C$. zeae-maydis DNA diluted in maize carrier DNA to a total of 10 ng DNA, respectively. Figure $\mathrm{c}$ indicates a standard curve for gst3 amplification from serial dilutions of maize genomic DNA

obtained for C. zeina and C. zeae-maydis cprl and for maize gst3.

qPCR quantification of $C$. zeina DNA in glasshouse inoculated maize leaves before and after lesion development

Amplification of the cprl gene by qPCR was undertaken in order to assess C. zeina content in maize 
leaves after inoculation with $C$. zeina in the glasshouse. DNA extractions were performed on three leaf segments (Fig. 4 a, b and c) with approximately 2, 4 and $16 \%$ infected leaf area, respectively, and subjected to $c p r 1$ and gst $3 \mathrm{qPCR}$. The amount of $C$. zeina DNA in each leaf sample was determined from a cprl standard curve (Fig. 3a), and normalised to the amount of maize DNA as calculated from a gst 3 standard curve (Fig. 3c). In this manner, leaf samples in Fig. 4 a-c were estimated to contain $4.7 \pm 0.3,7.8 \pm 1.1$ and $46.0 \pm$ $9.2 \mathrm{ng}$ C. zeina DNA/mg maize DNA, which was proportional to 2,4 and $16 \%$ infected leaf area, respectively. In addition, we were able to detect $C$. zeina DNA in inoculated maize leaves prior to the development of GLS symptoms (results not shown). These results verified that the qPCR assay using cprl and gst3 genes was an effective method for quantifying grey leaf spot disease in glasshouse experiments.

\section{C. zeina fungal content in GLS resistant and susceptible maize lines}

The qPCR assay was applied to quantify C. zeina in field infected maize leaves. Lesion area was determined for nine biological replicates from each of two maize inbred lines PEX1 and PEX2 (resistant and susceptible, respectively) (Fig. 4d and e) using digital image analysis. Differences in the number and area of lesions were observed between the two maize lines (Fig. $4 \mathrm{~d}$ and e). DNA was subsequently extracted from these samples and subjected to $c p r l$ and gst3 qPCR. The amount of C. zeina DNA was normalised relative to the amount of maize DNA ( $g s t 3$ qPCR), and a comparison was made to leaf lesion area (Fig. 5). There was good correlation between amount of $C$. zeina DNA and leaf lesion area (Pearson correlation= 0.76), and the quantification of $C$. zeina in the resistant maize line was significantly less than the susceptible line as determined by ng $C$. zeina/mg maize tissue (Student's $T$-test; $p<0.005$ ) and scanned lesion area (Student's $T$-test; $p<5 \times 10^{-5}$ ).

Implementation of qPCR assay to differentiate between C. zeae-maydis and C. zeina

GLS in maize is caused by both $C$. zeae-maydis and $C$. zeina. Sequence differences between $C$. zeina and $C$. zeae-maydis in the 164 bp cpr 1 amplicon (Fig. 1: nine nucleotides differ) allowed us to detect which of the two species was the causal agent of GLS on a symptomatic maize leaf. Melting curve analysis of known C. zeaemaydis and C. zeina isolates yielded significantly different single peaks of $85.28 \pm 0.07$ and $84.53 \pm 0.07$ respectively (two-tailed $T$-test, $p<0.05 \times 10^{-15}$ ) (Table 1 ; Supplementary Figure 2). Importantly, this differentiation was clear for a wide range of isolates tested, namely ten isolates of C. zeae-maydis from different sites in the USA, and 14 isolates of $C$. zeina from diverse sites in the USA and Africa, including samples amplified directly from GLS lesions (Table 1).
Fig. 4 Photographs of leaves with symptoms of GLS from glasshouse and field grown maize that were used for GLS disease quantification shown in Figure 5. Figures $\mathbf{a}, \mathbf{b}$ and $\mathbf{c}$ indicate leaf pieces with different areas of GLS lesions from glasshouse grown maize plants (hybrid PAN 6724B) at 19 days post inoculation with $C$. zeina. Figures $\mathbf{d}$ and e show leaf pieces of nine biological replicates each from two field grown maize lines PEX1 and PEX2 that are resistant and susceptible to grey leaf spot, respectively
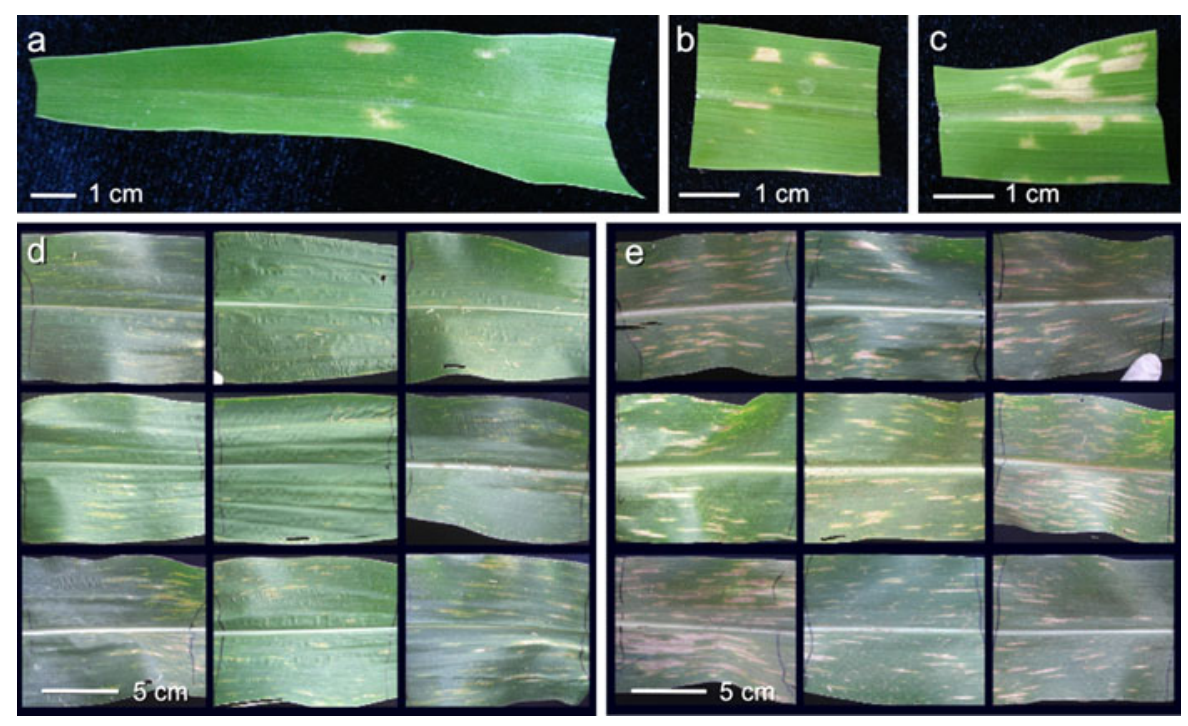

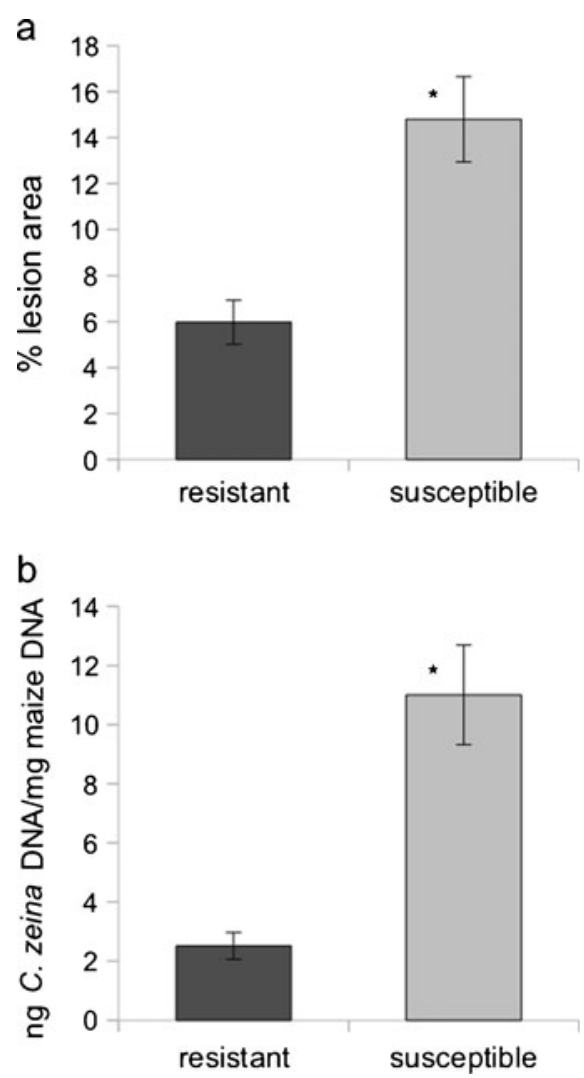

Fig. 5 Comparison of $C$. zeina infection in resistant and susceptible maize lines using a digital image analysis and $\mathbf{b}$ qPCR. a Nine biological replicate leaf pieces from each resistant (PEX1) and susceptible (PEX2) maize line were photographed and GLS lesion area relative to total leaf area was determined for the two lines. b Thereafter, DNA was extracted from these maize leaf pieces and subjected to the qPCR assay to determine ng Cercospora DNA per mg maize DNA. Bars on graphs indicate standard error. Asterisks indicate that the susceptible cultivar shows significantly different values to the resistant cultivar (Student's $T$-test; $p<0.005$ )

The qPCR assay was also successful in amplification of the $164 \mathrm{bp}$ cpr 1 product from a distinct Cercospora isolate from maize in South Africa, named Cercospora sp. CPC 12062 (Crous et al. 2006), which yielded a $\mathrm{Tm}=84.59 \pm 0.14$, which is not significantly different from C. zeina (Table 1; Supplementary Figure 2). This was to be expected since the sequences corresponding to the CPR1_2 primers were identical, and there was only one base pair difference between the 164 bp cpr 1 amplicons of these two species (Supplementary Figure 1).

An alternative differentiation between the two species known to be pathogens was evident from PCRRFLP analysis of the $164 \mathrm{bp}$ cprl product, since the $C$. zeae-maydis amplicon has two NlaIV sites whereas $C$. zeina (as well as Cercospora sp. CPC 12062; Supplementary Figure 1) has one NlaIV site. NlaIV digestion of the C. zeae-maydis amplicon yielded three fragments of 91, 39 and $34 \mathrm{bp}$, whereas the C. zeina amplicon yielded two fragments of 125 and $39 \mathrm{bp}$ (Supplementary Figure 3).

\section{Discussion}

In this study, we developed a qPCR method to detect and quantify $C$. zeae-maydis and $C$. zeina DNA in maize leaves. Primers were designed to a cytochrome P450 reductase gene (cprl) (Fig. 1), and the specificity was confirmed by testing against uninfected maize leaves and leaves infected with non-target maize pathogens (Fig. 2). Primers designed to the glutathione S-transferase III gene (gst3) from maize proved to be plant specific by the absence of cross-reaction with fungal DNA. Normalisation with the maize gst3 was performed to compensate for differences in the amount of maize DNA in each sample.

The functional role of the product of the cprl gene in Cercospora spp. is not yet known, although sequence similarity indicates that it has cytochrome p450 reductase activity. One of the ESTs from which the CPR1_1 primers were designed (AF448828) was initially annotated as $c t b 4$, one of the cercosporin biosynthesis genes (Shim and Dunkle 2002). However, this EST does not correspond to any of the three oxido-reductases of the well-characterized cercosporin biosynthetic cluster in Cercospora nicotianae (Chen et al. 2007). This was supported by the fact that the second EST (FG242129) was cloned from C. zeaemaydis growing vegetatively, which are conditions when cercosporin biosynthesis is repressed (Bluhm et al. 2008). CPR1 was first described in Aspergillus niger (GenBank accession number Z26938), and appears to be conserved in many fungal species (Supplementary Figure 1). Importantly, the gene regions corresponding to the primers used in the qPCR assay for quantifying Cercospora spp. in this study are sufficiently variable in other fungal species (Supplementary Figure 1), and were shown in our study to be specific to Cercospora spp. (Fig. 2).

De Coninck and co-workers (2011) recently developed a qPCR assay to detect and quantify Cercospora beticola in sugar beet cultivars. These authors utilised a Taqman ${ }^{\circledR}$ probe and associated primers to detect the 
Table 1 Melting temperatures of 164 bp qPCR products obtained with CPR1_2 primers from Cercospora spp. isolated from maize

\begin{tabular}{|c|c|c|c|c|c|}
\hline Species & Isolate no./code ${ }^{a}$ & Location $^{\mathrm{b}}$ & Year $^{\mathrm{c}}$ & $\operatorname{Tm}^{\mathrm{d}}$ & $\operatorname{aveTm}^{\mathrm{e}}$ \\
\hline \multirow[t]{10}{*}{ C. zeae-maydis } & CBS 117755 & Indiana, USA & 2003 & $85.27 \pm 0.05$ & \\
\hline & CBS $117757^{*}$ & Wisconsin, USA & 2000 & $85.31 \pm 0.03$ & \\
\hline & CBS 117758 & Iowa, USA & 2004 & $85.22 \pm 0.05$ & \\
\hline & CBS 117759 & Tennessee, USA & 1999 & $85.24 \pm 0.03$ & \\
\hline & CBS 117760 & Pennsylvania, USA & 1999 & $85.33 \pm 0.02$ & $85.28 \pm 0.07$ \\
\hline & CBS 117761 & Indiana, USA & 1999 & $85.33 \pm 0.02$ & \\
\hline & CBS 117762 & Missouri, USA & 2000 & $85.32 \pm 0.02$ & \\
\hline & CBS 117763 & Iowa, USA & 1999 & $85.33 \pm 0.03$ & \\
\hline & WB IL & Illinois, USA & - & $85.12 \pm 0.05$ & \\
\hline & WB KS & Kansas, USA & - & $85.32 \pm 0.06$ & \\
\hline \multirow[t]{17}{*}{ C. zeina } & CBS $118820^{*}$ & KZN, South Africa & 2005 & $84.48 \pm 0.05$ & \\
\hline & CMW 25442 & Art Farm, Zimbabwe & 2007 & $84.56 \pm 0.04$ & \\
\hline & CMW 25445 & Gart Farm, Zambia & 2007 & $84.52 \pm 0.02$ & \\
\hline & CMW 25452 & Karkloof, KZN, SA & 2007 & $84.49 \pm 0.03$ & \\
\hline & CMW 25454 & Karkloof, KZN, SA & 2007 & $84.45 \pm 0.02$ & \\
\hline & CMW 25459 & Winterton, KZN, SA & 2007 & $84.53 \pm 0.00$ & \\
\hline & CMW 25462 & Cedara, KZN, SA & 2007 & $84.44 \pm 0.01$ & \\
\hline & CMW 25463 & Greytown, KZN, SA & 2007 & $84.48 \pm 0.02$ & \\
\hline & CMW 25465 & Cedara, KZN, SA & 2007 & $84.49 \pm 0.06$ & $84.53 \pm 0.07$ \\
\hline & CMW 25466 & Karkloof, KZN, SA & 2007 & $84.56 \pm 0.03$ & \\
\hline & CMW 25467 & Mkushi, Zambia & 2007 & $84.51 \pm 0.02$ & \\
\hline & lesion DNA GF & Gart Farm, Zambia & 2010 & $84.65 \pm 0.01$ & \\
\hline & lesion DNA Mp & Mpongwe, Zambia & 2010 & $84.64 \pm 0.01$ & \\
\hline & lesion DNA Gtn & Greytown, KZN, SA & 2010 & $84.68 \pm 0.06$ & \\
\hline & WB VA & Virginia, USA & - & $84.49 \pm 0.01$ & \\
\hline & WB UG & Kamengo-Mpigi, Uganda & - & $84.49 \pm 0.04$ & \\
\hline & WB BZ & Goias, Brazil & - & $84.57 \pm 0.07$ & \\
\hline Cercospora sp. & CPC 12062 & KZN, South Africa & - & $84.59 \pm 0.14$ & \\
\hline
\end{tabular}

* ex-type cultures

${ }^{\mathrm{a}} \mathrm{CBS}=$ culture collection of the Centraalbureau voor Schimmelcultures (CBS), Utrecht, The Netherlands

$\mathrm{CMW}=$ culture collection of the Forestry and Agricultural Biotechnology Institute (FABI), University of Pretoria, South Africa

CPC: Culture collection of Pedro Crous, housed at CBS

$\mathrm{WB}=$ isolates from W-B. Shim

${ }^{\mathrm{b}}$ Location where the diseased maize material was collected

${ }^{\mathrm{c}}$ Year of GLS lesion collection

${ }^{\mathrm{d}}$ Melting temperature analyses were performed on the three technical replicates for each sample to obtain an average melting temperature and standard deviation

${ }^{\mathrm{e}}$ Melting temperatures for isolates from each species were averaged to obtain a species melting temperature

C. beticola calmodulin gene in infected sugarbeet material. Fungal DNA levels were normalised to levels of an endogenous sugar beet DNA sequence. As was the case with our study, these authors found a significant correlation between fungal DNA levels and leaf lesion area, as well as a significant difference between $C$. beticola levels in susceptible and resistant sugar beet cultivars. Their assay is of particular value in glasshouse screening of sugar beet in which the inoculum is limited to $C$. beticola. Although the 
authors state that the qPCR assay did not amplify from two other Cercospora species, it was not tested in field experiments. In contrast, we have demonstrated our qPCR assay to be specific and effective in maize fieldgrown material (Figs. 2, 4 and 5), conditions under which screening for quantitative resistance to this disease is most desirable.

Our qPCR assay was sensitive, and could detect the target pathogen in as little as $5 \mathrm{pg}$ DNA for both C. zeaemaydis and C. zeina (Fig. 3). This represents an improvement in sensitivity compared to other DNA based detection methods such as dot blots that were able to detect 160 pg of DNA from Sporisorium reiliana, the cause of head smut in maize (Xu et al., 1999). Alternative approaches that are not based on DNA are less sensitive, such as ELISA-based assays (Ward et al., 2004) or measurement of the fungus-specific lipid ergosterol, which has been used for quantification of Cercospora kikuchii in soybean (Xue et al., 2006). Ergosterol is present in many fungal species, and thus its use is limited to controlled inoculations. In contrast, our qPCR assay is specific to Cercospora spp. from maize, and therefore can be applied in field experiments.

A detection limit of $5 \mathrm{pg}$ for both C. zeae-maydis and C. zeina in our qPCR assay corresponds to approximately 125 genome equivalents. This is based on the assumption that both species have a genome size of $\sim 40 \mathrm{Mb}$. This was the average genome size for ten of twelve sequenced Dothidiomycete genomes (March 2011; www.osti.gov/bridge/purl.cover.jsp?purl=/ 1012481-8TJMwv/). Nicolaisen et al. (2009) achieved a lower detection limit of 2.5 genome equivalents $(0.1 \mathrm{pg})$ for Fusarium spp. in maize using primers to the elongation factor 1 alpha gene. A TaqMan ${ }^{\circledR}$ PCR assay based on $c p s D$ from the maize pathogen Pantoea stewartii was able to detect $1 \mathrm{pg}$ of purified P. stewartii DNA, the equivalent of $10^{4}$ colony forming units per millilitre (Tambong et al. 2008). We were unable to compare the sensitivity of our qPCR assay with that for C. beticola, as De Coninck et al. (2011) based their detection limits on $\Delta \mathrm{Ct}$ values calculated by subtracting the $\mathrm{Ct}$ value of an endogenous sugar beet control from the $\mathrm{Ct}$ value of the $C$. beticola calmodulin gene.

C. zeae-maydis and C. zeina are closely related species, which both cause GLS in maize, but occur in different geographic regions. We have recently confirmed that $C$. zeina remains the causal agent of GLS of maize in southern Africa and that absence of $C$. zeae-maydis is highly likely (Meisel et al. 2009). Since occurrence of both Cercospora species in one field is rare and has only been reported for some locations in Ohio and New York in the U.S.A. (Wang et al. 1998), it is not crucial that the quantitative assay presented here cannot quantify $C$. zeina and $C$. zeae-maydis separately within a sample. Sequence analysis of the 164 bp cprl-amplicon revealed nine bp differences between the two Cercospora species (Fig. 1). These sequence differences allowed us to employ melt curve analyses to distinguish between species, and could be utilised to detect a mixed infection within a maize leaf (Table 1; Supplementary Figure 2). There was only one base pair difference between the cprl amplicon from C. zeina and Cercospora sp. CPC 12062, a distinct isolate from maize in South Africa (Crous et al., 2006)(Supplementary Figure 1), and thus these two species could not be distinguished based on Tm (Table 1; Supplementary Figure 2). It is not known if this isolate is a pathogen on maize, however it would be quantified by the qPCR assay if present.

Resistance to grey leaf spot disease is generally quantitative in nature (Balint-Kurti et al., 2008), and it has been suggested that an understanding of the molecular basis of quantitative disease resistance requires exploitation of maize genetic diversity combined with improved phenotyping approaches (Poland et al., 2009). The qPCR assay reported here represents a tool that can be applied in this type of "precision phenotyping" approach for assessment of both QTL and association mapping populations of maize for quantitative resistance to GLS (Rafalski 2010).

We have demonstrated the use of a qPCR assay based on the cprl gene to quantify GLS disease in maize. In this manner, we were able to show good correlation between $C$. zeina DNA levels and GLS lesion area on maize leaves in the glasshouse and field. Because of its specific, precise, cost-effective and fast nature, the assay presented here will be a useful tool in grey leaf spot disease management, breeding programmes and plant-pathogen interaction studies, and thus mitigate the threat of this pathogen to food security in maize producing countries of the world.

Acknowledgments The financial assistance of the Technology Innovation Agency (TIA), the National Research Foundation (NRF) and the University of Pretoria (UP), South Africa, towards this research is hereby acknowledged. Opinions expressed and conclusions arrived at, are those of the authors and are not necessarily to be attributed to TIA, NRF or UP. We thank W-B. Shim for DNA from Cercospora spp., and T.G. Schmidt for digital image analysis. 
Open Access This article is distributed under the terms of the Creative Commons Attribution Noncommercial License which permits any noncommercial use, distribution, and reproduction in any medium, provided the original author(s) and source are credited.

\section{References}

Altschul, S. F., Gish, W., Miller, W., Myers, E. W., \& Lipman, D. J. (1990). Basic local alignment search tool. Journal of Molecular Biology, 215, 403-410.

Balint-Kurti, P. J., Wisser, R., \& Zwonitzer, J. C. (2008). Use of an advanced intercross line population for precise mapping of quantitative trait loci for gray leaf spot resistance in maize. Crop Science, 48, 1696-1704.

Bluhm, B., Dhillon, B., Lindquist, E., Kema, G., Goodwin, S., \& Dunkle, L. (2008). Analyses of expressed sequence tags from the maize foliar pathogen Cercospora zeae-maydis identify novel genes expressed during vegetative, infectious, and reproductive growth. BMC Genomics, 9, 523.

Brunelli, K. R., Dunkle, L. D., Sobrinh, C. A., Fazza, A. C., \& Camargo, L. E. A. (2008). Molecular variability in the maize grey leaf spot pathogens in Brazil. Genetics and Molecular Biology, 31, 938-942.

Chen, H., Lee, M. H., Daub, M. E., \& Chung, K. R. (2007). Molecular analysis of the cercosporin biosynthetic gene cluster in Cercospora nicotianae. Molecular Microbiology, 64, 755-770.

Crous, P. W., Groenewald, J. Z., Groenewald, M., Caldwell, P., Braun, U., \& Harrington, T. C. (2006). Species of Cercospora associated with grey leaf spot of maize. Studies in Mycology, 55, 189-197.

De Coninck, B. M. A., Amand, O., Delaur, S. L., Lucas, S., Hias, N., Weyens, G., Mathys, J., De Bruyne, E., \& Cammue, B. P. A. (2011). The use of digital image analysis and real-time PCR fine-tunes bioassays for quantification of Cercospora leaf spot disease in sugar beet breeding. Plant Pathology. doi:10.1111/j.1365-3059.2011.02497.x.

Dunkle, L. D., \& Levy, M. (2000). Genetic relatedness of African and United States populations of Cercospora zeae-maydis. Phytopathology, 90, 486-490.

Goodwin, S. B., Dunkle, L. D., \& Zismann, V. L. (2001). Phylogenetic analysis of Cercospora and Mycosphaerella based on the internal transcribed spacer region of ribosomal DNA. Phytopathology, 91, 648-658.

Latterell, F. M., \& Rossi, A. E. (1983). Gray leaf spot of corn: a disease on the move. Plant Disease, 67, 842-847.

Meisel, B., Korsman, J., Kloppers, F. J., \& Berger, D. K. (2009). Cercospora zeina is the causal agent of grey leaf spot disease of maize in southern Africa. European Journal of Plant Pathology, 124, 577-583.

Moller, E. M., Bahnweg, G., Sandermann, H., \& Geiger, H. H. (1992). A simple and efficient protocol for isolation of high molecular weight DNA from filamentous fungi, fruit bodies, and infected plant tissues. Nucleic Acids Research, 20, 6115-6116.

Nicolaisen, M., Suproniene, S., Nielsen, L. K., Lazzaro, I., Spliid, N. H., \& Justesen, A. F. (2009). Real-time PCR for quantification of eleven individual Fusarium species in cereals. Journal of Microbiological Methods, 76, 234-240.
Okori, P., Fahleson, J., Rubaihayo, P. R., Adipala, E., \& Dixelius, C. (2003). Assessment of genetic variation among East African Cercospora zeae-maydis. African Crop Science Journal, $11,75-85$.

Poland, J. A., Balint-Kurti, P. J., Wisser, R. J., Pratt, R. C., \& Nelson, R. J. (2009). Shades of gray: the world of quantitative disease resistance. Trends in Plant Science, 14, 21-29.

Rafalski, J. A. (2010). Association genetics in crop improvement. Current Opinion in Plant Biology, 13, 174-180.

Shim, W. B., \& Dunkle, L. D. (2002). Identification of genes expressed during cercosporin biosynthesis in Cercospora zeae-maydis. Physiological and Molecular Plant Pathology, 61, 237-248.

Shim, W. B., \& Dunkle, L. D. (2005). Malazy, a degenerate, species-specific transposable element in Cercospora zeaemaydis. Mycologia, 97, 349-355.

Tambong, J. T., Mwange, K. N., Bergeron, M., Ding, T., Mandy, F., Reid, L. M., \& Zhu, X. (2008). Rapid detection and identification of the bacterium Pantoea stewartii in maize by TaqMan real-time PCR assay targeting the $c p s D$ gene. Journal of Applied Microbiology, 104, 1525-1537.

Van Den Brink, H. M., Van Zeijl, C. M. J., Brons, J. F., Van den Hondel, C. A. M. J. J., \& Van Gorcom, R. F. M. (1995). Cloning and Characterization of the NADPH Cytochrome P450 Oxidoreductase Gene from the Filamentous Fungus Aspergillus niger. DNA and Cell Biology, 14, 719-729.

Waalwijk, C., Koch, S., Ncube, E., Allwood, J., Flett, B., de Vries, I., \& Kema, G. (2008). Quantitative detection of Fusarium spp. and its correlation with fumonisin content in maize from South African subsistence farmers. World Mycotoxin Journal, 1, 39-47.

Wang, J., Levy, M., \& Dunkle, L. D. (1998). Sibling species of Cercospora associated with gray leaf spot of maize. Phytopathology, 88, 1269-1275.

Ward, E., Foster, S. J., Fraaije, B. A., \& McCartney, H. A. (2004). Plant pathogen diagnostics: immunological and nucleic acid-based approaches. Annals of Applied Biology, 145, 1-16.

Ward, J. M. J, Birch, E. B. \& Nowell, D. C. (1994). Grey leaf spot on maize. Pietermaritzburg, South Africa. Coordinated extension, Maize in Natal, Cedara Agricultural Development Institute.

Ward, J. M. J., Stromberg, E. L., Nowell, D. C., \& Nutter, F. W., Jr. (1999). Gray leaf spot. A disease of global importance in maize production. Plant Disease, 83, 884-895.

White, T. J., Bruns, T., Lee, S., \& Taylor, J. (1990). Amplification and direct sequencing of fungal ribosomal RNA genes for phylogenetics. In M. A. Innis et al. (Eds.), PCR Protocols: a guide to methods and applications (pp. 315-322). California: Academic.

Xu, M. L., Melchinger, A. E., \& Lnbberstedt, T. (1999). Species-specific detection of the maize pathogens Sporisorium reiliana and Ustilago maydis by dot blot hybridization and PCR-based assays. Plant Disease, 83, 390-395.

Xue, H. Q., Upchurch, R. G., \& Kwanyuen, P. (2006). Ergosterol as a quantifiable biomass marker for Diaporthe phaseolorum and Cercospora kikuchii. Plant Disease, 90, 1395-1398.

Zhu, X., Reid, L. M., \& Woldemariam, T. (2002). First report of gray leaf spot caused by Cercospora zeae-maydis on corn in Ontario, Canada. Plant Disease, 86, 327. 